\title{
Proyecto de restauración de la capilla del Convento de las Monjas Comendadoras para Auditorio Municipal. Brozas (Cáceres). Fases | y ||
}

\section{Ma del Carmen Díez González}

Universidad de Extremadura

RESUMEN

San Pedro en Brozas fue convento de las monjas de la Orden Militar de Alcántara. Se empezó a construir a finales del siglo XVI, pero el templo no se concluyó hasta el fin del XVIII. El templo fue desamortizado y desacralizado en 1836. A finales del siglo XX se compró y cedió al Ayuntamiento de Brozas para Auditorio Municipal. El año 1999 comenzó la restauración y rehabilitación del edificio. Este trabajo dura hasta la actualidad.

PALABRAS CLAVE: Arquitectura Religiosa s. XVI-XVIII/ Restauración/ Órdenes Militares

Projects for restoring the Chapel of Comendadora's Convent in Brozas (Cáceres, Spain) and its adaptation for Municipal Auditory

ABSTRACT

Saint Peter in Brozas was a convent that belonged to the nuns of Alcantara's Military Order. This building started to be built at the end of the 16th Century and was finished at the end of the 18th Century. The Temple was seized and debunked in 1836. At the end of the 20th Century, the building was bought and transferred to Brozas' City Council to be used as Municipal Auditorium. The restoration and renovation of the building started in 2001 and continues nowadays. Order KEY WORDS: Religious Architecture XVI-XVIII th./ Restoration/ Military

Al oeste de la provincia de Cáceres se alza Brozas, un enclave histórico artístico en la ruta que une la capital de la provincia con la que fuera importante plaza fuerte de Alcántara (N 521 - C 523). Su importancia estratégica, militar y económica, en las proximidades de la frontera con Portugal, fue determinante para que la Orden de Alcántara situara en esta población la Encomienda Mayor. Razón por la que se le dotó de un castillo y cerca de piedra que circundaba toda la villa.

En las inmediaciones de una de las puertas de la fortaleza, abierta al sur, se construyó el convento de San Pedro, la segunda fundación de freiras pertenecientes a dicha Orden Militar, filial de la de Sancti Spiritus (31-VIII-1518), la primera comunidad de monjas caballeras ${ }^{1}$. Estas monjas ocuparon en Alcántara el viejo edificio con-

* DíEZ GonZÁLEZ, Ma del Carmen: "Proyecto de restauración de la capilla del Convento de las Monjas Comendadoras para Auditorio Municipal. Brozas (Cáceres). Fases I y II", en Boletín de Arte, $\mathrm{n}^{\circ} 29$, Departamento de Historia del Arte, Universidad de Málaga, 2008, págs. 113-133.

1 Se las denominaba de este modo porque era requisito indispensable para profesar en la Orden ostentar el título de nobleza. 


\section{2 artículos $\quad M^{a}$ del Carmen Díez González}

ventual abandonado por los freires cuando estos se trasladaron al de San Benito. Tales fundaciones femeninas fueron poco frecuentes entre las órdenes militares y de hecho en la alcantarina no hubo más.

San Pedro figura en el inventario de Bienes Inmuebles del Patrimonio Histórico y Cultural de Extremadura. Se conserva la casa conventual, cuyo solar y edificio se reparten entre una vivienda particular y el Centro de Educación Infantil. Esta última parte, propiedad del Ayuntamiento, acoge también el Servicio Extremeño Público de Empleo (SEXPE) y otras asociaciones culturales y de ocio. Por otro lado se están rehabilitando, como Auditorio Municipal, la iglesia y algunas dependencias anejas a las que se une un huerto por la parte trasera. Se inscribe el inmueble en una manzana, en pleno casco histórico, y dentro de esta, la capilla ocupa la esquina noroeste [1]. Su advocación ha dado nombre a la calle que flanquea el muro norte, a la cual se abre la portada principal del templo. La cabecera de este y el huerto, en cambio, lindan con la calle Aldehuela.

La iniciativa de restauración y rehabilitación de la iglesia como Auditorio Municipal partió del propio Ayuntamiento de Brozas. A tal efecto la Caja de Ahorros de Extremadura, con cargo a la Obra Socio Cultural, adquirió y cedió el edificio², puesto que era de propiedad particular. De este modo la Consejería de Cultura de la Junta de Extremadura acometió el proyecto en varias fases, cofinanciado con los fondos FEDER de la Unión Europea. En la actualidad continúan las obras de adecuación para el citado fin.

\section{HISTORIA DE CONVENTO.}

El promotor, don Pedro Gutiérrez Flores ${ }^{3}$, oriundo de Brozas, pertenecía a una de las más distinguidas familias brocenses. Había profesado en la Orden Militar de Alcántara y en ella se distinguió al actuar de Secretario en varios capítulos. Alcanzó hacia 1561 el rango de Sacristán Mayor, la tercera dignidad (sujeta sólo al Prior y al Gran Maestre $)^{4}$, cargo que llevaba anejo el título de Capellán de Honor del rey y que él vino a ejercer en tiempos de Felipe $\|^{5}$.

Sensible al movimiento de espiritualidad que se vivía en España durante el siglo XVI, la piedad de este caballero le llevó a fundar un convento femenino en su

\footnotetext{
2 Se solicitó una subvención de 9.000 .000 de pts., que cubrían el gasto de adquisición, el gasto notarial y el de registro. Archivo Municipal de Brozas (A.M.B.), "Expediente de Restauración de la capilla del convento de las Comendadoras para auditorio". Carta del Alcalde al Presidente de la Caja de Ahorros de Extremadura, 29-V-1996.

3 Archivo Histórico Nacional (A.H.N.), Órdenes Militares (O. M.), leg. 3693, 2, "Expediente sobre reedificación del convento de San Pedro de la villa de Brozas", carta de 18-X-1735.

4 La dignidad de Gran Maestre fue ostentada por el monarca desde 1494, como Administrador Perpetuo de todas las Órdenes Militares.

5 A.H.N., O. M., Libro de Visitas, 1578-1579, sig. 453 c. Vid. Etiam. CARRASCO MONTERO, G.: "Desamortización del Real Convento de San Pedro de las Comendadoras del hábito y caballería de la Orden de Alcántara en la Encomienda Mayor de las Brozas. Cáceres", Memoria Eccesiae XXIII, Oviedo, 2003, pág. 371.
} 


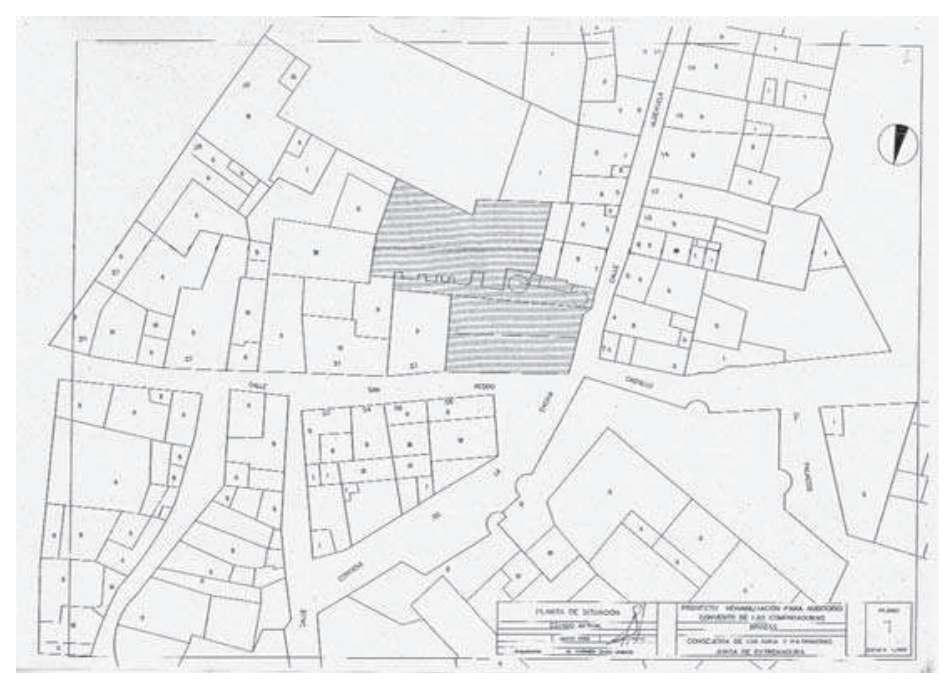

1. Convento de San Pedro de Brozas (Cáceres). Plano de situación de la iglesia.

patria chica, para que pudieran ingresar allí las hijas de los cofrades, con la gracia especial de no precisar más que el aporte de 150 maravedíes y una cama como dote 6 . Una contribución que se elevaba a 100 ducados para las damas que no tuvieran relación con la Orden?

Entre las razones expuestas en la fundación, don Pedro alegaba la ventaja de la proximidad que representaba tener a las novicias y profesas "a la vista" 8 de sus parientes, pues de otro modo deberían ingresar en conventos más alejados.

Se sabe que don Pedro maduraba su propósito desde al menos $1561^{9}$, pero no logró exponerlo oficialmente hasta el Capítulo General que la Orden celebró el año 1570 en Toledo ${ }^{10}$. Allí obtuvo el permiso verbal del monarca Felipe II, condicionado, como era costumbre, a la justificación de los medios económicos indispensables para la subsistencia. A tal efecto el fundador legaba sus bienes el 6 de octubre de 1578 a través de un testamento ${ }^{11}$.

6 CARRASCO MONTERO, G.: "Comendadoras de Alcántara -rama femenina de la Orden- en las Brozas", XXXI Coloquios históricos de Extremadura, 2003, pág. 116.

7 Ibídem.

8 Ibídem, pág. 120

9 CARRASCO MONTERO, G.: “Desamortización del Real Convento...”, op. cit., pág. 371.

10 A.H.N., O.M., Ibídem.

11 Ibídem. Etiam. CARRASCO MONTERO, G.: “Desamortización ...”, op. cit., pág. 372. 


\section{Q: artículos $\quad M^{a}$ del Carmen Diez González}

La muerte de don Pedro sin embargo alargó el proceso hasta 1586, año en el que el Visitador de la Orden, don Bartolomé de Villavicencio, a través del tío y el tutor de los bienes de don Pedro, comprobó la licencia y las posibilidades económicas del cenobio $^{12}$, tras lo cual dispuso con las autoridades alcantarinas todo lo necesario para llevar a efecto la fundación. Así en 1589 se autorizaba el alzamiento de la fábrica13; al año siguiente se redactan las escrituras de fianza14 y se firman las condiciones en $1592^{15}$; y finalmente, en 1593 , se pregonan y rematan las obras ${ }^{16}$.

Las fechas coinciden con la presencia y trabajos en la fortaleza y murallas de Brozas de un afamado y destacado arquitecto: Juan Bravo (150-1596), Maestro Mayor de la Orden de Alcántara ${ }^{17}$, hijo ilustre de la villa, quien, si no dio las trazas, al menos debió supervisar los planos del convento.

Se puede considerar la fundación en firme a partir del 1 de abril de 1594 , fecha en la que el Prior del Convento de Alcántara, don Pedro Barrantes, traslada a Brozas cuatro comendadoras residentes en el Espíritu Santo de la misma villa y les asigna los cargos en la nueva casa ${ }^{18}$.

El legado de don Pedro y su sucesor en el vínculo propiciaron el inicio de la fábrica del templo en sillería. Sin embargo, muerto el sucesor, comenzaron las dificultades económicas para rematar la iglesia y la morada definitiva de las monjas ${ }^{19}$. El óbito de tres de las fundadoras (1605) complicó aún más el desarrollo de la comunidad de San Pedro que estuvo a punto de desparecer20. Por ello otras tres religiosas de Sancti Espiritu fueron enviadas a la casa de Brozas y se quedaron en ella hasta que creció el número de postulantas 21 .

\footnotetext{
12 Ibídem.

13 A.H.N., O.M, leg. 3693, 3.

14 Ibidem.

15 Ibídem.

16 Ibídem.

17 Sánchez Lomba señala que ese mismo año de 1593 "lo encontramos presentando las condiciones -acompañadas de dibujos explicativos- para la remodelación de la Casa de la Encomienda Mayor de Brozas". Lo considera, además, uno de los mejores arquitectos del siglo XVI en Extremadura. Formado con el gran Pedro de Ybarra, participó probablemente en las obras de San Benito de Alcántara. También en Santa Maria y Santos Mártires de Brozas. A la muerte de Ybarra fue nombrado Maestro Mayor de la Orden de Alcántara y de la Diócesis de Coria. Emite informes en las parroquias de Rocamador de Valencia de Alcántara, la de Zarza la Mayor y la de Gata. Actúa en la catedral de Coria. Sobre las actuaciones de Juan Bravo Vid. SANCHEZ LOMBA, Iglesias caurienses del milquinientos, Cáceres, Institución Cultural el Brocense, 1994, pág. 77. Etiam, NAVAREÑO MATEOS: Arquitectura y arquitectos del siglo XVI en Extremadura. Proyectos de obras de de la Orden de Alcántara, Madrid, Universidad de Extremadura, Colegio Oficial de Arquitectos de Extremadura, 1994, págs. 18-19. Podemos atribuirle también intervenciones en el convento de Nuestra Señora de la Luz, casa capitular de los franciscanos descalzos de la Provincia de San Gabriel. Cfr. DIEZ GONZÁLEZ, C.: Brozas y el convento de la Luz, Madrid, Afegir, S.A., 1994, págs. 36-37 y 53 .

18 Estos fueron los de: Abadesa, Priora, Portera y, a la cuarta, la doble función de Sacristana y Cantora. Vid. A.H.N., O.M, Ibídem., sig. 453 c, visitas de 1758-1759.

19 Ibídem., leg. 3693, 2. "Expediente sobre reedificación de el convento de San Pedro de la villa de Brozas", $18-\mathrm{X}-1735$

20 CARRASCO MONTERO, G.: “Desamortización...”, op. cit., pág. 375.

21 lbídem.
} 
Don Pedro había previsto en su testamento una comunidad de 22 monjas 22 , pero el estallido de la guerra de Secesión del reino luso respecto a la Corona española (1640-1668) truncó sus deseos que se vieron sensiblemente reducidos. A la escasez de recursos, que obligó a destinar parte de la dote de las novicias a gastos de alimentos ${ }^{23}$, se sumó el impago de las rentas dirigidas a la edificación, pues una gran parte de los bienes que las producían se asentaban sobre el propio escenario de batalla 24 . Por el mismo motivo tampoco llegaron los socorros del Rey25, que debieron emplearse en la lucha; y, para colmo, al término de las hostilidades, en 1678 , todos los ingresos y materiales destinados a la obra del templo se aplicaron al "reparo y fortificación de la Casa Fuerte de la Encomienda"26.

A fines del siglo XVII el convento constaba de una elemental capilla y unas exiguas piezas alzadas en "tapia de tierra" 27 . A la espera de reunir los suficientes recursos económicos para construir el templo "principal" un informe sin fecha, inserto en el libro de Visitas de 1758-1759, ofrece una clara visión de lo que se había alzado:

"Causa grande lástima que estando en tan buen estado la fabrica de la iglesia que esta por acabar, de este monasterio no se pueda finalizar por falta de medios. Las medidas de lo obrado en ellas según la declaracion de los maestros se reduce a que el largo es de vente y una varas y el ancho por el altar mayor ha de tener diez varas y tercia y para el coro doce varas. Las paredes tienen de alto ocho varas y tercia y para el coro doce varas. Las paredes tiene de alto ocho varas y dos de grueso por la parte de arriva y por la de abajo cinco. La sacristía tiene de ancho cuatro varas y tres de fondo y las dos capillas de los colaterales cuatro varas y media, de ancho y tres de fondo toda esta obra según el estado que representa, en alberca y sin techumbre es de piedra corta y con buenas mezclas de admirable disposizion, y tambien se registra casi finalizada la Portada que ha de servir al Publico, de dicha iglesia con unas columnas de jaspe blanco y la hechura del apóstol San Pedro, por frente con otras molduras"28.

Con las arcas exhaustas y sin materiales para rematar el templo las comendadoras de Brozas comenzaban el nuevo siglo haciendo frente a otro conflicto bélico importante, la Guerra de Sucesión al Trono español (1700-1714), que dio paso al cambio dinástico. El 27 de febrero de 1706, el Consejo de Órdenes solicitaba con máxima urgencia al rey 600 ducados para sostener el culto divino y la manutención

\footnotetext{
22 A.H.N., O.M, Libro de Visitas, 1758-1759, sig. 453 c.

23 Ibíd., leg. 3693, 2. Carta del Consejo de Órdenes a su Majestad, 27-II-1706.

24 Ibídem. Informe del Contador, 1678.

25 El rey cedió a las monjas la encomienda de Azebuche. Ibídem.

26 Ibídem. Memorial de la Comunidad.

27 Ibídem., leg. 3693, 3, Informe de Theosio de Magalães, 22-IX-1744

28 Ibídem, Visitas, año 1558-1559, f. 246.
} 


\section{Q: artículos $\quad M^{a}$ del Carmen Diez González}

de las monjas caballeras de San Pedro 29 . Se trataba pues de la supervivencia de la comunidad religiosa, no de continuar la fábrica de la iglesia renacentista. De nuevo las yerbas y juros de las que obtenían rentas habían quedado en la frontera con Portugal, país aliado del pretendiente austriaco, y la toma de las plazas de Alburquerque y Valencia de Alcántara en esas fechas impedían su arriendo ${ }^{30}$. La situación se volvió angustiosa cuando, el 7 de abril de ese mismo año, los portugueses conquistan la plaza de Brozas. En medio del tumulto saquean, queman las viviendas y exigen a las caballeras que entreguen los vasos sagrados para salvarse de sus atropellos ${ }^{31}$.

El 22 de diciembre de 1713 se ordenaba por Cédula Real pregonar la paz con los vecinos lusos y reintegrar a las monjas de San Pedro los ducados que se le adeudaban con varios atrasos ${ }^{32}$. Pero la dureza de la contienda había arruinado la zona, dejando exhaustas las arcas de la Orden de Alcántara y los concejos de su jurisdicción. El impago de la deuda persistió aún varios años más ${ }^{33}$. En 1720 asumía el patronato don Matías Gutiérrez Vargas y Aldana, quien asignó cuatro monjas a la casa, por haberse reducido la comunidad a tan solo dos. Pero el nuevo patrón no ayudó a solventar los problemas económicos y el deterioro del inmueble ${ }^{34}$ fue en aumento.

La capilla provisional se desmoronaba y alcanzó un grado peligroso de deterioro en 1721, año en el que la abadesa solicita su reparo y la asignación de alguna encomienda vacante para hacer frente a los daños ${ }^{35}$. Pero no obtuvo respuesta. Así el 22 de julio de 1735 informa nuevamente sobre la amenaza de ruina en la pared principal de la misma capilla, que separaba la iglesia del convento, y el traslado inmediato del Santísimo al locutorio, una pieza muy próxima a la portada principal de la casa ${ }^{36}$. Por temor al desplome la comunidad solicitó incluso el informe de un Maestro de Obras de Garrovillas $^{37}$. El 9 de enero de 1736 se remite al Consejo de Ordenes Militares un Real Decreto por el que se cede a las religiosas la encomienda del Peso Real de Valencia de Alcántara "para reparar y reedificar con sus rentas la referida iglesia", pero en mayo el Consejo resuelve permutar la cesión por otra de menor rendimiento 38 .

El 15 de junio del mismo año, el Real Consejo acuerda 39 rematar la iglesia del quinientos y el 29 de dicho mes se notifica a la abadesa y comunidad 40 . Entre tanto se intentó que el patrón asumiera el gasto ${ }^{41}$ pero ante su negativa se le retira esta gracia $(1744)^{42}$.

29 Ibídem, leg. 3693, 2. “Expediente sobre reedificación”, 18-X-1735.

30 Ibídem.

31 Ibídem. Expediente sobre la reedificación de el convento de San Pedro de la villa de Brozas", 18-X-1735.

32 Ibidem.

33 Ibídem., leg. 3693, 2, Solicitud de la abadesa de 1715

34 Para el reparo de la fábrica solicitaba la abadesa la asignación de la renta de alguna encomienda vacan-

te. Ibídem.

35 Ibídem.

36 Ibídem

37 Ibídem.

38 La de Portezuelo. Ibídem, leg. 3693, 2. Acuerdo de 27-V-1736.

39 Ibídem. Acuerdo del Real Consejo de Órdenes, 15-VI-1736.

40 Ibídem

41 Ibídem., 27-VII-1742.

42 lbídem 
2: artículos Proyecto de restauración del convento de las Monjas...

Dos arquitectos locales, Alonso González y Juan de Escandón, emitieron un informe el 9 de noviembre de dicho año43. Se Señalan en el informe diversos reparos utilizando la fábrica de la "iglesia empezada" y se aconseja no derribar la "vieja" para evitar gastos ${ }^{44}$. Se sucede después la visita de Theodosio de Magalães, "maestro de arquitectura" 45 de origen portugués, natural de Ponte de Limia, personaje que por entonces estaba revisando la iglesia parroquial de la vecina localidad de Navas del Madroño. Por petición del Real Consejo de las Órdenes, don Theodosio emite un informe donde se dictamina que la iglesia provisional amenaza ruina por tener las paredes interiores y exteriores muy viejas y carcomidas, formadas por tapial. Tampoco juzga suficientes los cimientos ni el volumen de la misma, por lo que propone construir otra de nueva planta reutilizando la caja de los muros del templo renacentista inconcluso. Junto con la descripción de la nueva iglesia añade la planta y el alzado46 de la misma. Magalães traza un templo sencillo, barroco clasicista, sin grandes adornos, para reducir gastos.

La planta es rectangular, con cabecera cuadrada y tres tramos de naves; el tercero de ellos, sobre el que iría el coro, es más corto. El presbiterio sobresale en altura y se adorna con una "media naranja" sobre pechinas y linterna. Se adosa al muro del segundo tramo la sacristía de planta cuadrangular y cubierta de semiesfera.

En el alzado refleja el interior de la pared norte. Dispone los muros articulados a través de pilastras toscanas, sobre las que montan fajones y las cubiertas a base de bóvedas de medio cañón con lunetos. Se resalta que habría que construir los soportes: "por hallarse sin ellas [las pilastras] ni estribos algunos en las paredes". Junto a la portada principal, situada en el segundo tramo de la nave, aparece en el alzado otro vano menor que existe actualmente cegado. Del otro lado, según la planta, se abría la puerta reglar. Pero los restos que han llegado al momento presente demuestran que no se siguieron estas trazas del maestro portugués. Sólo hacia 175047 debió cubrirse el templo con una bóveda de sección carpanel.

Veinte años más tarde (1764), la situación de las caballeras llegó a tal extremo que pretendieron sustraerse de la jurisdicción del Prior y subrogarse a la del Obispo de Coria48. La comunidad se redujo a tan sólo dos religiosas, de modo que en el curso de la Primera Guerra Carlista (1833-1840), el propio Ayuntamiento de Brozas propuso desplazar a las monjas a una casa particular y alojar la tropa en el

\footnotetext{
43 Ibídem., leg. 3693, 2, "Expediente de reedificación del convento de San Pedro de la villa de Brozas" 44 Ibídem

45 Ibídem, leg. 3693, 3. Sobre este arquitecto y proyecto vid. DIEZ GONZÁLEZ, Ma del C.: "Propuesta de reforma en la iglesia del convento de San Pedro de Brozas (Cáceres) por Theodosio de Magalães". NorbaArte, XXV, en prensa. Etiam. MARTín NIETO, D. A., "Noticias de artistas del siglo XVIII en los territorios de la Orden de Alcántara", Revista Alcántara, nº 58, pág. 28.

46 Vid. DIEZ GONZÁLEZ, Ma del C., "Propuesta de reforma...", en prensa.

47 A.H.N., OO. MM., Orden de Alcántara, sig. 1535, Visita del Monasterio de San Pedro de Brozas, 1750.

48 "Los dos conventos de religiosas de Brozas y Valencia de Alcántara [sic], sujetos al Prior son los más infelices así por la falta de rentas, como por la Dirección; y aunque han solicitado venirse a mi filiación no les he dado oidos por el pleito pendiente entre mi Dignidad y el Orden de Alcántara". Vid. Archivo Diocesano de
} 
convento ${ }^{49}$. El incidente motivó la protesta del Prior de Alcántara ${ }^{50}$, alegando al efecto que no encontraba acomodo a las monjas y que existían otros edificios disponibles más apropiados para albergar a la milicia.

Tras la desamortización decretada por Mendizábal la morada de las freiras se destinó desde 184451 a escuelas públicas de ambos sexos ${ }^{52}$. Hacia 1920 era colegio para pobres regentado por las carmelitas ${ }^{53}$, bajo cuya dirección estuvo unos cincuenta años. Entre tanto, la iglesia se redujo a una lechería ocupada por vacas y sus reservas de alimento. En esta etapa debieron rebajarse las jambas de la puerta principal para permitir el paso de vehículos en su interior y se sustrajeron las columnas que la flanqueaban. Posiblemente se eliminó también el enlosado de granito, si lo tuvo, y se practicó el ventanal de la cabecera. A finales del siglo XX la iglesia y un huerto colindante eran de propiedad particular. Abandonada y demiderruida la adquirió el Ayuntamiento en 199654 .

\section{DESCRIPCIÓN DEL EDIFICIO AL INICIO DE LAS OBRAS55.}

El templo [2] se orientó a poniente, dejando exentas la cabecera y el muro de la epístola. A grandes rasgos forma en planta un rectángulo irregular, de unos veinticuatro por doce metros en la parte del presbiterio, rectángulo que aumenta a catorce en los pies. El solar se asienta en un terreno basculado hacia el mediodía y oriente. Linda al norte con la calle San Pedro, al este con la vivienda conventual, trasformada como ya se indicó, al sur con el huerto interior, y, al oeste, con la calle Aldehuela y otras viviendas.

El interior de la nave aparece diáfano. Hacia poniente unos muretes estrechan la embocadura de la cabecera, siendo esta rectangular y compartimentada en tres espacios: la capilla mayor más amplia y dos oratorios colaterales. En el lado del evangelio se adosa otro cuerpo o nave rectangular, en el que se suceden de este a oeste tres estancias, y una escalera de San Gil, a través de la cual se accede a las cubiertas. El gran grosor de los muros y el desvío entre los diversos espacios inducen a pensar en sucesivas readaptaciones del ámbito litúrgico.

\footnotetext{
Coria-Cáceres (A.D.C-C.), leg. "Conventos". Carta del Obispo de Coria, 6-V-1764.

49 A.H.N., OO. MM., leg. 3693, "Carta del Ayuntamiento de Brozas a la Reyna", 24-II-1834.

50 Ibídem, Cartas de 28-II-1834; Orden de acuartelamiento en el monasterio de 28-II-1834; Orden del Prior para que no se lleve a efecto de 12-III-1834; otras en los mismos términos de 13-III-1834; Notificación en la que se insiste en que no tenga efecto la orden militar, 17 de marzo de 1834.

51 Por entonces el inmueble constaba de 26 áreas. CARRASCO MONTERO, G., "Desamortización del Real Convento...", op. cit., pág. 379.

52 CARRASCO MONTERO, G.: "Desamortización del Real Convento...", op. cit., pág. 379.

53 Ibídem.

54 (Archivo Municipal de Brozas (A.M.B.). Informe al Presidente de la Caja de Ahorros de Extremadura. Memoria del Proyecto de restauración de la capilla del convento de las monjas comendadoras en auditorio. Brozas (Cáceres), 1996.

55 Como el reconocimiento del inmueble ha sido efectuado cuando ya se había desarrollado todo el programa de rehabilitación se toman como referencia preferente los planos de "Situación actual" y las descripciones de la memoria de la primera fase del proyecto, redactada con mayor detalle que otras descripciones.
} 


\section{artículos

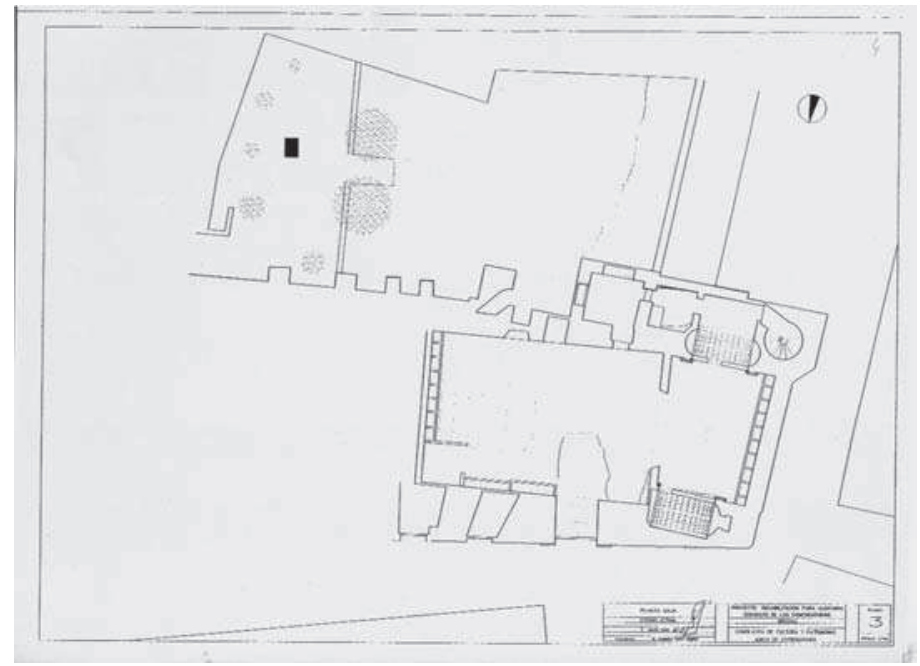

2. Convento de San Pedro de Brozas (Cáceres). Planta baja de la iglesia. Estado actual, $M^{a}$ DEL CARMEN SANZ JIMENO.

Externamente [3], los muros suben unos cinco metros y medio. El lienzo norte construido en sillería remata en una cornisa. Destaca en él la portada principal [5]. El ingreso se abre bajo arco de medio punto, con labor de caja, flanqueado por altos podios sobre los que iban dobles columnas corintias con fustes monolíticos de material noble ${ }^{56}$. Entre el espacio de los soportes se desarrolla una estrecha hornacina rematada en venera y dividida por una repisa convexa a media altura. Por encima corre el arquitrabe con friso de mármol y una inscripción: "QVI TRANSIS CAVE NFSI LEAS AVE M". Remata en templete avenerado con frontón triangular, que sobresale por encima de la cornisa. La capilla acogió la imagen de mármol de San Pedro, desaparecida en la actualidad. En las enjutas se inscriben medallones con sendos bustos, femenino el de la derecha y masculino el de la izquierda [6]. Forma todo el conjunto una pieza de talla delicada y buena cantería. En el mismo lienzo, hacia oriente aparece otro pequeño arco con acceso a la nave, cegado; y al otro lado de la portada, hacia poniente, un escudo dividido en cuatro cuarteles, de algún personaje perteneciente a la Orden, pues monta sobre cruz flordelisada.

El muro occidental [7] fue construido con sillares regulares, incluida la caja de

56 Posiblemente mármol, aunque no se ponen de acuerdo las fuentes. Cif. A.H.N., O.M., Visitas, 1758-1759, sig. 453, f. 246; Ibídem, leg. 3693, 3, Informe de Theodosio de Magalães", 22-IX-1774. 


\section{Q: artículos $\quad M^{a}$ del Carmen Diez González}

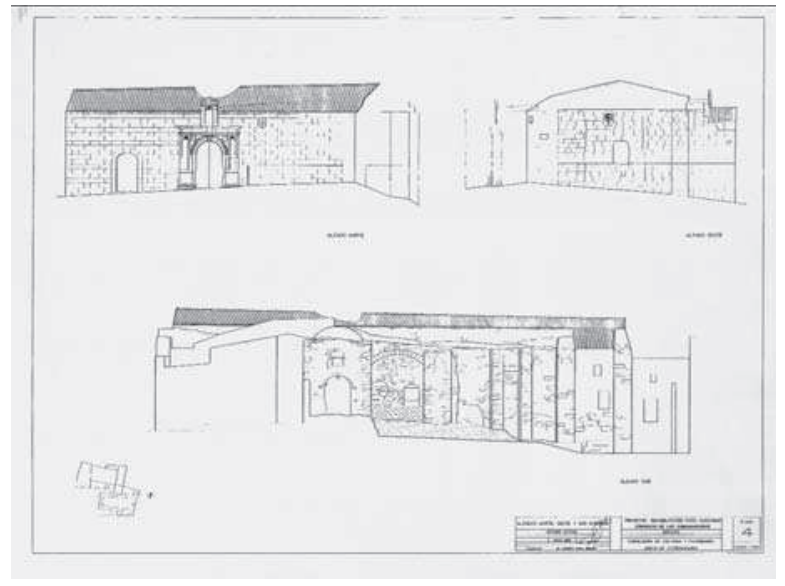

3. Convento de San Pedro

de Brozas (Cáceres).

Alzados de la iglesia.

Estado actual, $M^{a}$ DEL

CARMEN SANZ JIMENO.

las escaleras. En el centro, cerca de la cornisa se colocó otro escudo. Pero la esquina norte y la zona próxima a las cubiertas se construyeron con mampostería. En la pared sur [3] se muestra una gran diversidad de materiales: cantería, mampuestos de diversos tamaños y ladrillos. Este lado se refuerza con arcos de entibo y cuatro contrafuertes desiguales, anárquicamente dispuestos.

Al interior, el nivel del suelo desciende unos cincuenta centímetros respecto a la calle. Obstaculizaban el espacio de la nave numerosos pesebres situados en los pies y lo mismo ocurría con el testero de la capilla mayor [2] La cubierta del buque forma una bóveda de cañón de sección carpanel. En cuanto a la cabecera, el presbiterio conserva dos ménsulas platerescas con borrosos rostros de angelotes [6], posiblemente por estar expuestos a la intemperie largo tiempo. Debían haber servido como responsiones de una bóveda de crucería, que se alzó de aristas. En los muros norte y sur se disponen las capillas adyacentes [7] de poca profundidad, cubiertas con bóvedas de cañón encasetonadas y hornacinas que rematan en veneras en los lados menores. La del lateral sur comunica con las capillas adosadas al cuerpo de la nave y en el lienzo occidental una portada con frontón triangular da acceso a la escalera de San Gil [8], de buena cantería, que finaliza en la cubierta plana de esta zona.

En el lado del evangelio se abre un oratorio cubierto con cúpula rebajada, que posiblemente sirvió de sacristía; le sigue hacia el norte un camarín techado con medio cañón. Este último espacio comunica con la cabecera a través un ensanchamiento de la capilla colateral sur.

El inmueble sufría un manifiesto deterioro general, con desplomes en la bóveda de la nave mayor [3], la cubierta y su armadura prácticamente en ruinas y con restos de arreglos efectuados sin criterio alguno. Las bóvedas de los oratorios del lado sur se hallaban hormigonadas y también lo estaba en parte el trasdós de la cúpula. 


\section{Q: artículos $\quad$ Proyecto de restauración del convento de las Monjas...}
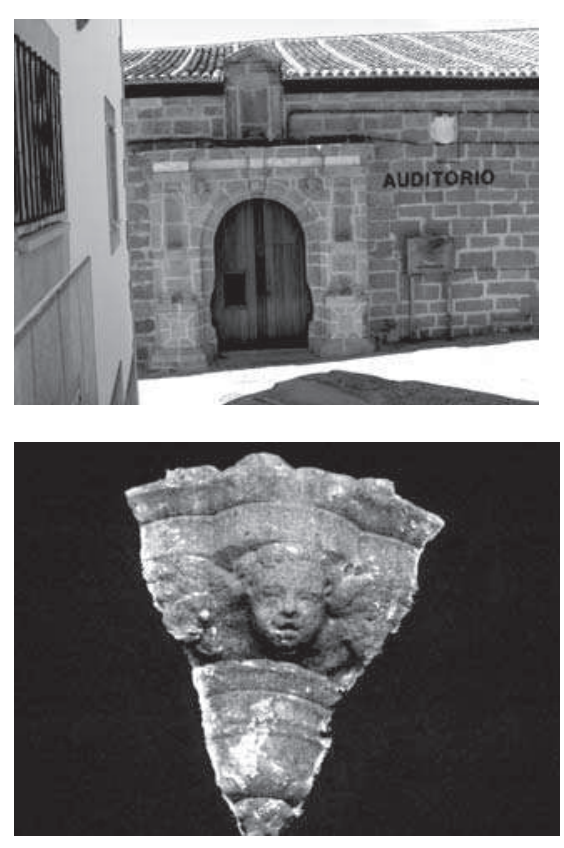

4-7. Convento de San Pedro de Brozas (Cáceres). 4. Portada principal de la iglesia.

5. Portada principal de la iglesia (detalle).

6. Iglesia. Ménsula de la cabecera.

7. Iglesia. Cabecera, capilla colateral norte (detalle).
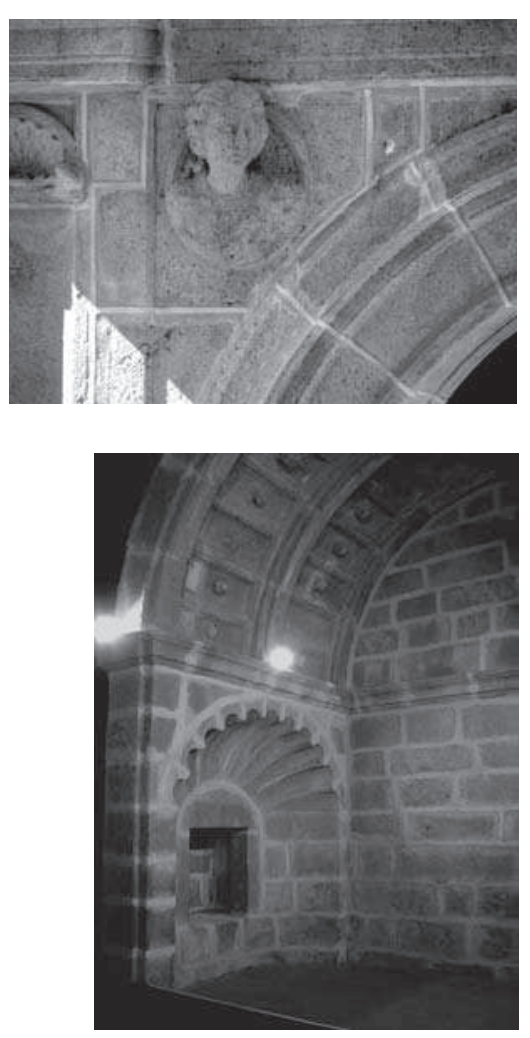

El lienzo sur lindante con el huerto aparecía invadido por la vegetación y el material disgregado. En los demás paramentos se había perdido el mortero de cohesión entre los sillares, mampuestos y ladrillos, e incluso parte del material. El que subsistía presentaba los bordes erosionados por la acción combinada de la lluvia y el viento. En el muro occidental dos juntas prácticamente verticales y diferencias en las hiladas testimoniaban el haber sido demolida esta parte y posteriormente repuesta. Por la altura a la que se encuentran podrían hacer pensar en un posible hueco para abrir un camarín o, con mayor criterio, una ventana para ventilar la estancia cuando se dedicaba el edificio a lechería. Especialmente dañadas estaban la esquina noroeste, las cornisas y la parte superior del cerramiento de la escalera; en este último caso por el desagüe directo de la azotea que había producido derrumbes y humedades.

En el interior, los daños debidos a falta de estanqueidad dieron lugar a fenómenos de helacidad, caolinización y oxidación, causando la disgregación y arenitización de los materiales y diversas costras, que provocaron pérdida del espesor en los 


\section{Q: artículos $\quad M^{a}$ del Carmen Diez González}

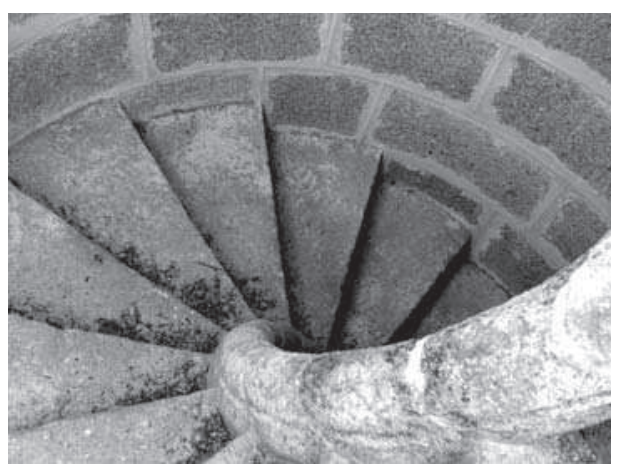

8. Convento de San Pedro de Brozas (Cáceres). Iglesia. Escalera de San Gil.

sillares y falta de cohesión entre ellos. Los muros aparecían descarnados, dejando a la vista la diversidad de la fábrica. Eran también visibles eflorescencias y sales hidratadas en las superficies expuestas al agua de lluvia y capilaridad.

En cuanto al suelo, resultaba imposible determinar el original, debido al considerable espesor de la capa de tierra vegetal y escombros que lo cubría.

Los corrales se encontraban también invadidos por la maleza, cascotes y piedras desplomadas de los propios muros.

\section{INTERVENCIONES.}

Dentro de las Normas subsidiarias municipales el inmueble está catalogado con el NIVEL I, por lo que sobre estos terrenos:

"Se prohibe cualquier acto de edificación y uso del suelo, salvo los encaminados a la dignificación y puesta en valor de elementos de protección... conservación y mejora... En consecuencia sólo podrán autorizarse obras de restauración, conservación y consolidación, pudiendo autorizarse obras de reconstrucción de elementos preexistentes y demolición de elementos postizos no integrados en el conjunto en las condiciones establecidas en el art. 143", según el cual se prevé que "se respetarán las características esenciales del inmueble" y "se respetarán las características volumétricas y espaciales definitorias del inmueble" 57.

De acuerdo con la normativa, el proyecto contempla:

a) La restauración del interior actual del templo para adecuar su uso como auditorio 58 , acoplando el patio de butacas en la nave y el escenario en la capilla

57 A.M.B., "Normas subsidiarias de reedificación". Todo ello concuerda con el art. 33 de la Ley de Patrimonio Histórico y Cultural de Extremadura 2/1999, de 29 de marzo de 1999; también con la Carta de Cracovia 2000, punto 6.

58 La utilización de los monumentos para funciones útiles a la sociedad es una norma aconsejada por multitud de recomendaciones internacionales. Por ejemplo la Carta de Atenas, 1931, 2; Carta de Venecia, 1964, art. 5; Carta Europea del Patrimonio Arquitectónico, 26/09/1975, principios 6 y 7; Carta de Cracovia 2000, 


\section{Q artículos $\quad$ Proyecto de restauración del convento de las Monjas...}

mayor y sus colaterales.

b) La construcción de los nuevos pabellones de servicios, respetando el entorno conventual que aún se mantiene 59 .

c) La restauración de los jardines 60 .

Su importe económico aconsejó desarrollarlo en tres etapas.

\section{Primera fase.}

Corrió bajo la supervisión de la arquitecta $\mathrm{M}^{\mathrm{a}}$ del Carmen Sanz Gimeno61, a cargo de la Consejería de Cultura y Patrimonio de la Junta de Extremadura. Constituyó el proyecto titulado "Rehabilitación e Intervención Auditorio Capilla del Convento de las Comendadoras, en Brozas (Cáceres)". Acometió los trabajos referentes a la fábrica del templo, que consistieron en "la consolidación, limpieza, demoliciones de añadidos, restauración de bóvedas, la reparación y sustitución de cubiertas planas e inclinadas, su sistema de desagües, la cubrición de la escalera de acceso a la cubierta y el desvío del tendido eléctrico, y estudio arqueológico"62. Todo ello previsto en el plazo de dos años.

A las actuaciones previas correspondieron el desbroce, limpieza y excavación del terreno por medios manuales, con la recuperación de materiales y su aprovechamiento, llevándose a cabo tanto en el interior como en el exterior del templo y en los jardines ${ }^{63}$. Se elaboró así un estudio histórico ${ }^{64}$ y arqueológico a pie de obra para el control de desescombro y la realización de prospecciones selectivas ${ }^{65}$. Fue practicado por la arqueóloga Ana Hernández Carretero en todo el interior de la capilla y proporcionó un conocimiento más detallado de la edificación, reparaciones, reconstrucciones y la planta de esta pieza. No se logró alcanzar el enlosado, tal vez no lo tuvo o simplemente se le expolió como las columnas de la entrada. Pero sirvió para detectar algunas zonas de especial significado en la capilla y aconsejar su revalorización 66 .

En cuanto a las demoliciones ${ }^{67}$ se efectuaron sobre los pesebres y algunos tabiques para acceder a los jardines. Así, hacia la mitad del muro del evangelio, donde se abría un hueco profundo, se trepanó el fondo para dar paso a la zona

\footnotetext{
punto 3, Carta de la conservación y restauración de los objetos de arte y cultura, 1987, anejo A, punto 2.

59 Art. 18 de la Ley de Patrimonio Histórico Español 16/1985, 24 de junio de 1985, respecto a los BIC.

60 lbid.

61 Colegiada entonces en Madrid. Ha sido imposible contactar con ella y saber qué otras actuaciones en materia de rehabilitación ha realizado.

62 A.M.B., Arquitecto M $\mathrm{M}^{\mathrm{a}}$ del Carmen SANZ GIMENO, 'Memoria' del Proyecto "Auditorio del Convento de las Comendadoras", 1999, pág. 2.

63 Ibídem, "Antecedentes y datos generales", pág. 4.

64 Cumple con ello la normativa autonómica. Vid. Art. 32, de la Ley de Patrimonio Histórico y Cultural de Extremadura 2/1999, de 29 de marzo de 1999.

65 Ibídem.

66 Ibídem, Arquitecto Ma Victoria DOMÍNGUEZ SERRANO, "Proyecto de restauración de la capilla del convento de las monjas comendadoras en Auditorio, Brozas (Cáceres)”, Fase 2, 2002, pág. 5.

67 Ibídem, SANZ JIMENO, C., 'Memoria', op. cit., pág. 4
} 


\section{Q: artículos $\quad M^{a}$ del Carmen Diez González}

nueva que acogía los aseos. El oratorio colateral a la nave, cubierto con cúpula, se transformó en vestíbulo. De este modo da acceso, por una parte, a la nueva edificación que alberga los camerinos, locales de instalaciones y almacenaje y, por otra, a través del camarín, comunica con la capilla colateral sur de la cabecera y el caracol.

Se picaron también parte de las coronaciones de los muros de mampostería, necesarios para la colocación de la nueva cubierta. Así mismo se procedió el desmonte del material de los tejados con la recogida del mayor número posible de teja vieja, con su limpieza y apilamiento para su reutilización posterior. Se demolieron igualmente algunas pendientes de las cubiertas planas para regularizarlas después. También se desmontó el tendido eléctrico que actualmente apoya en la fachada del convento68.

Respecto a las bóvedas se procedió a su retacado, comprendiendo en esta tarea el picado perimetral de las zonas degradadas, desmontaje de ladrillos sueltos, limpieza para enjarjes y reposición pieza a pieza, por taqueo, con ladrillo de tejar, recibido con mortero bastardo. La zona perdida de la bóveda se reconstruyó con dos roscas de ladrillo de tejar $(3,8 \mathrm{~cm}$.), recibido la primera con pasta de yeso y la segunda con mortero bastardo mixto. El intradós se trató con una capa de mortero bastardo de $1,5 \mathrm{~cm}$. de espesor, armada con tela metálica "tipo gallinero", claveada sobre el soporte del mortero. A esta capa se adosó un aislante acústico para atenuar ruidos de impacto, realizado con fieltro de lana de vidrio pegado a un panel alquitranado69. Este recubrimiento pesado y rígido causaría problemas como se verá más adelante.

En los paramentos se procedió a la limpieza de la coronación de los muros de mampostería y la cornisa de piedra, donde se aplicó un producto "desincrustantedecapante", frotado con cepillo de raíces para eliminar manchas y residuos. A lo que siguió un tratamiento con herbicida y fungicida en profundidad, rematando con un tratamiento de impermeabilización a base de acetato de vinilo ${ }^{70}$.

La cornisa de piedra natural fue previamente limpiada con aire a presión y aspirador. Se le aplicó después morteros especiales rematando en terraja. Tras lo cual se repuso el material perdido -diferenciado en un tono más claro-71, y se recolocó en su sitio el que se había roto o desplazado ${ }^{72}$. Por último, se reconstruyeron los muros de mampostería en su coronamiento a base de mampostería ordinaria de piedra caliza, a una cara vista, con recuperación de piezas de demolición [9]. Todo ello recibido con mortero bastardo y diferenciado con un color más claro ${ }^{73}$.

En el límite de los muros se colocó un perfil metálico [10] como remate superior lineal de las fachadas, con tratamiento de oxirón negro sobre plancha metálica de 3 milímetros ${ }^{74}$. Absorbe de este modo las diferencias de pendientes originadas por la

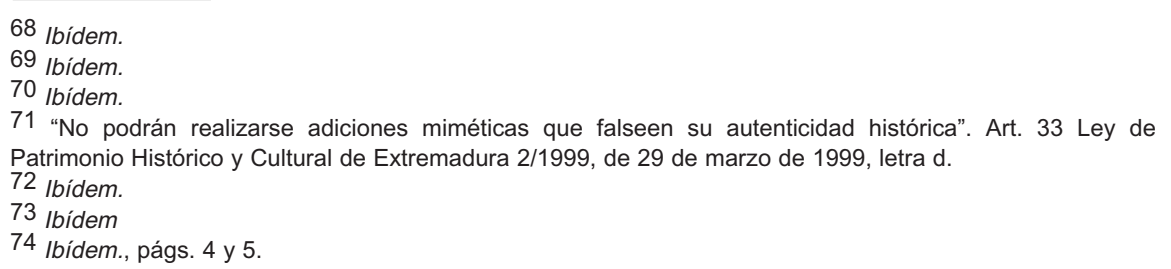




\section{2: artículos Proyecto de restauración del convento de las Monjas...}

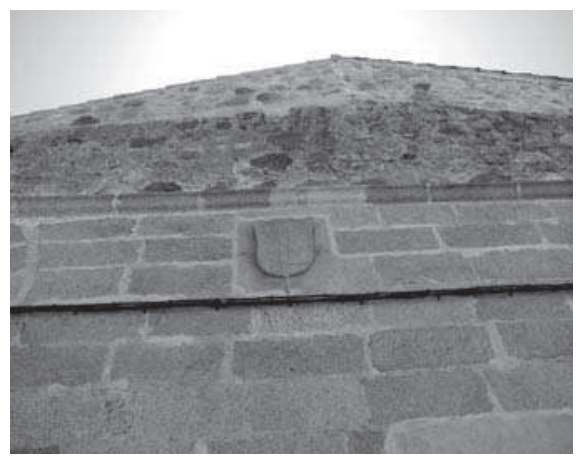

9. Convento de San Pedro de Brozas (Cáceres). Muro oeste (detalle).

10. Convento de San Pedro de Brozas (Cáceres). Portada principal de la iglesia (detalle).

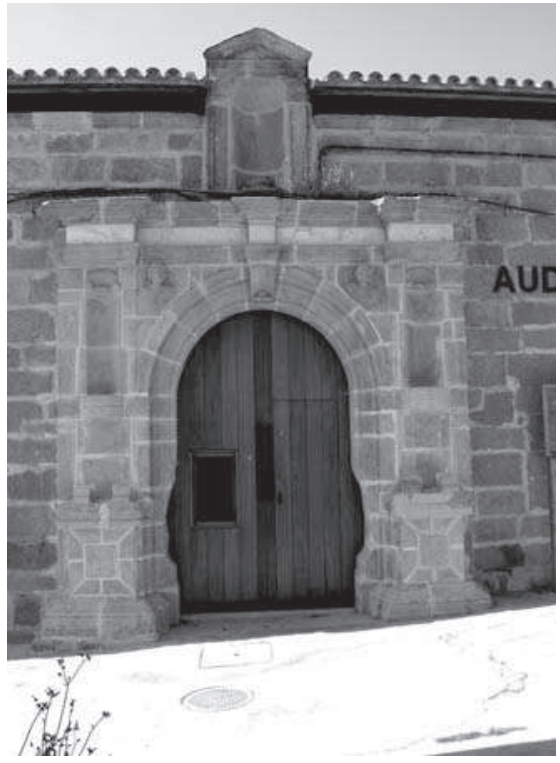

irregularidad de la planta y la altura de las bóvedas. Sobre este perfil carga la nueva cubierta del templo utilizando una estructura de cerchas de madera laminada, protegida debidamente con tratamiento hidrófugo, ignífugo y fungicida sobre la cual se colocaron las tejas empleando las antiguas como cobijas y las nuevas como canales ${ }^{75}$.

En cuanto a las cubiertas planas se empleó "hormigón celular", más lámina asfáltica, e imprimación asfáltica, con conexión a paramentos verticales y colocación de los canalones. La escalera de caracol se cubrió con una marquesina [11] constituida por perfiles de acero laminado, chapa lisa de acero de 10 milímetros, tratada de forma que absorba ruidos de impacto rígido. El acabado de los elementos metálicos se realizó con tratamiento de oxirón negro forja ${ }^{76}$.

\section{SEgunda fase.}

Se emprendió trascurrido un año de la finalización de la primera, en 2001. Bajo la dirección ahora de la arquitecto $M^{a}$ Victoria Domínguez Serrano ${ }^{77}$, y en ella se acometieron los siguientes objetivos: adecuación del espacio de la antigua capiIla del Convento de las Monjas Comendadoras para auditorio de uso municipal. Completando la actuación con la ejecución de nuevas dependencias que albergaran

\footnotetext{
75 Ibídem.

76 Ibídem, pág. 5.

77 Colegida en Extremadura, esta arquitecta ha realizado intervenciones puntuales en el ámbito de la restauración dentro de la Consejería de Cultura de la Junta de Extremadura, como esta segunda fase del
} 


\section{Q: artículos $\quad M^{a}$ del Carmen Diez González}

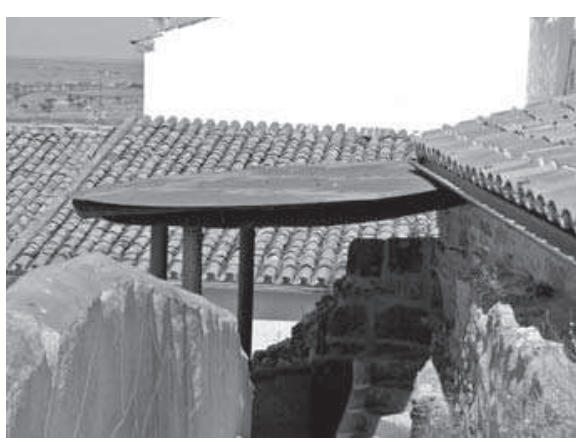

11. Convento de San Pedro de Brozas (Cáceres). Marquesina. $M^{a}$ DEL CARMEN SANZ JIMENO.

los camerinos, aseos, locales de instalaciones y almacenaje para el correcto funcionamiento del auditorio ${ }^{78}[12,13,14]$. Pero alcanzó solamente al equipamiento de la sala del auditorio y los aseos.

Los nuevos volúmenes, situados en el patio anejo que comunica la capilla con el antiguo convento, van destinados a albergar el programa funcional y ordenar el patio para poder utilizarlo como auditorio abierto, y nexo de unión entre el antiguo convento y el auditorio. El cuerpo de los camerinos se tratará como fondo de escenario del auditorio abierto y como posible pantalla de proyección 79 . Tales pabellones forman aproximadamente una "U" adosada al edificio principal.

Pero al comienzo de esta fase el edificio de la iglesia presentaba algunas deficiencias respecto a la actuación primera. Los tableros de cubierta habían flectado por el excesivo peso de la bóveda y la escasa inercia frente a las luces que debían salvar, por lo que descendieron y hundieron la techumbre provocando humedades ${ }^{80}$. También se produjeron filtraciones de agua, a través de la escalera de husillo que alcanzaron la capilla mayor con entradas de agua y arrastre de sales ${ }^{81}$. Por otra parte, la excavación arqueológica había dejado al descubierto la cimentación en 1,60 metros ${ }^{82}$.

Debido a ello hubo que realizar una serie de tareas para consolidar las estructuras existentes, así como nuevas cimentaciones para las nuevas estructuras y el alzamiento de esta últimas.

Entre los trabajos de consolidación se llevó a cabo el recalce de cimentación de muros, pues aunque al inicio de la fase presentaban buenas condiciones de estabilidad, los trabajos arqueológicos habían dejado al descubierto las cimentaciones de la edificación alcanzando una profundidad de 1,60 metros en toda la nave y en casos puntuales

Proyecto del Auditorio. Intervino también en la pavimentación en el Casar de Cáceres. Se caracteriza por utilizar métodos tradicionales muy respetuosos.

78 Ibídem, DOMíNGUEZ SERRANO, Mª V., "Proyecto de restauración ...", pág. 4.

79 Ibídem.

80 lbídem.

81 Ibidem.

82 Ibídem. 


\section{2: artículos Proyecto de restauración del convento de las Monjas...}

12. Convento de San Pedro de Brozas (Cáceres). Iglesia. Planta baja. Estado reformado.

$M^{a}$ VICTORIA DOMÍNGUEZ SERRANO.

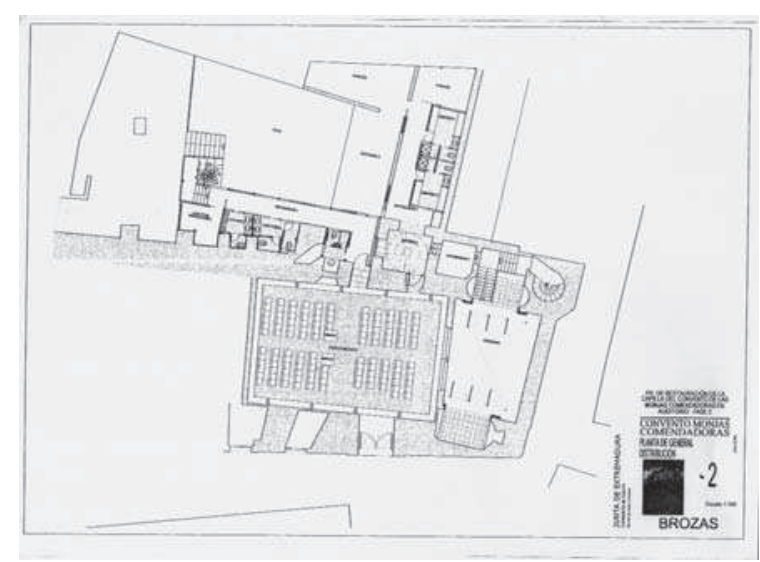

hasta 3,20 m. Se dictaminó así el relleno con la tierra sustraída y para asegurar la inestabilidad previsible en algunos puntos, se planteó la ejecución de un muro de ladrillo macizo corrido, como un anillo interno de los muros, tomado con mortero de cal para evitar aportes de sales a la mampostería y evitar arrastres de las mismas estructuras ${ }^{83}$.

Así mismo se procedió a un tratamiento interior de los muros con eliminación de juntas antiguas en profundidad y regularización del rejuntado de la mampostería irregular con mortero de cal grasa. Donde existían pérdidas de material o irregularidades se procedió a la aplicación conjunta de diversos materiales. Con ello se garantizaba la planitud del muro para recibir los revocos de cal, aplicados sobre la mampostería, ladrillo y zonas de materiales mixtos, dejando vista la cantería y elementos decorativos ${ }^{84}$. Las sales existentes en la superficie de la piedra sillar se trataron con cepillo y agua limpia85.

Al exterior se procedió a la limpieza de las juntas, eliminando la vegetación existente y juntas antiguas en una profundidad suficiente para el agarre de las nuevas, rejuntando con mortero de cal grasa, tipo junta enrasada ${ }^{86}$, con textura y color claro diferente al que tenían.

En el interior de la capilla se procedió a construir el forjado del suelo [15] a base de madera con viguería y escuadrías de pino sobre estructura metálica. Sobre la viguería va doble entablado de paneles de contrachapado hidrófugo, en dirección perpendicular, sobre ellos un filtro no tejido para absorción del ruido de impacto. El forjado se termina con entarimado de roble ${ }^{87}$. En el escenario [16] el acabado se sustituye por pane-

\footnotetext{
83 Ibídem, pág. 8.

84 Ibídem, págs. 8-9

85 Ibídem, pág. 9.

86 Ibídem.

87 Ibídem, pág. 10.
} 


\section{2: artículos $\quad M^{a}$ del Carmen Diez González}

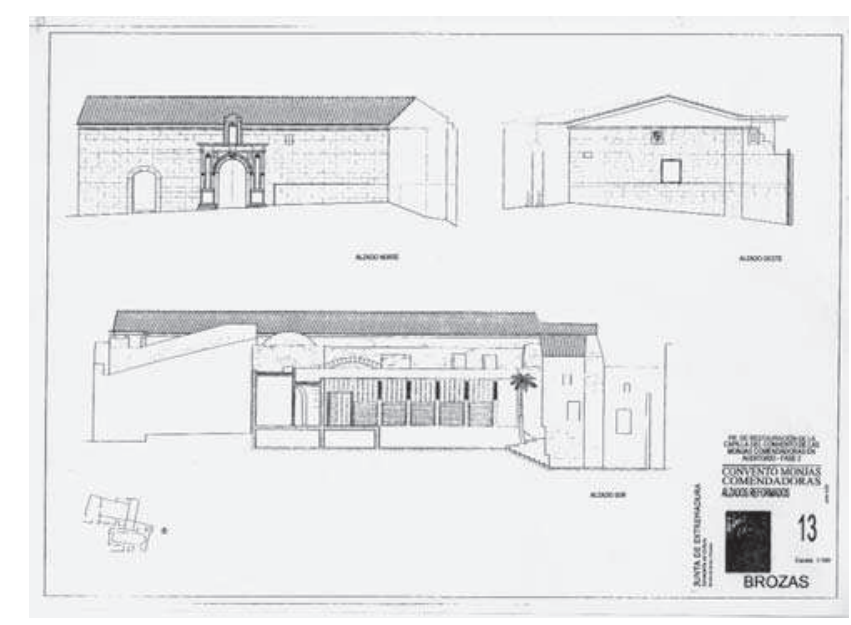

13. Convento de San Pedro de Brozas (Cáceres). Iglesia. Alzados. Estado reformado. $M^{a}$ VICTORIA DOMínGUEZ SERRANO.

les de 'ocumene' tratado con pintura negra mate de fondo de escenario 88 .

Los pabellones de aseos montan sobre zapata rígida de hormigón armado con mallazo ${ }^{89}$ dispuesto entre los contrafuertes del muro del evangelio de la capilla.

Actualmente se acomete el pabellón de camerinos y el de almacenes, también sobre zapata de hormigón armado y las paredes construidas con perfiles metálicos y soportes en cajón anclados a la cimentación, soldados con placas de chapas de acero. Los huecos de luz se perfilan con planchas de metal. Sin embargo, como se encuentran en curso las obras, se considerará en otro estudio la ejecución de ambos pabellones.

\section{JUICIO CRITICO.}

El inmueble reúne buenas condiciones para el fin previsto, como espacio suficiente, entorno adecuado para un auditorio y los accesos perfectamente practicables ${ }^{90}$. Además la nueva dedicación recupera el uso unitario del espacio sagrado y sus anejos $^{91}$ y ayudará a preservar este destacado bien cultural y su singular memoria.

Respecto a la primera intervención la arquitecto se ha movido entre el respeto al monumento y la innovación. Así juzgamos coherente el desarrollo de los circuitos, que

\footnotetext{
88 Ibídem.

89 lbídem.

90 Art. 32. 4, de la Ley de Patrimonio Histórico y Cultural de Extremadura 2/1999, de 29 de marzo de 1999.

91 Art. 32, a), de la Ley de Patrimonio Histórico y Cultural de Extremadura 2/1999, de 29 de marzo de 1999.
} 


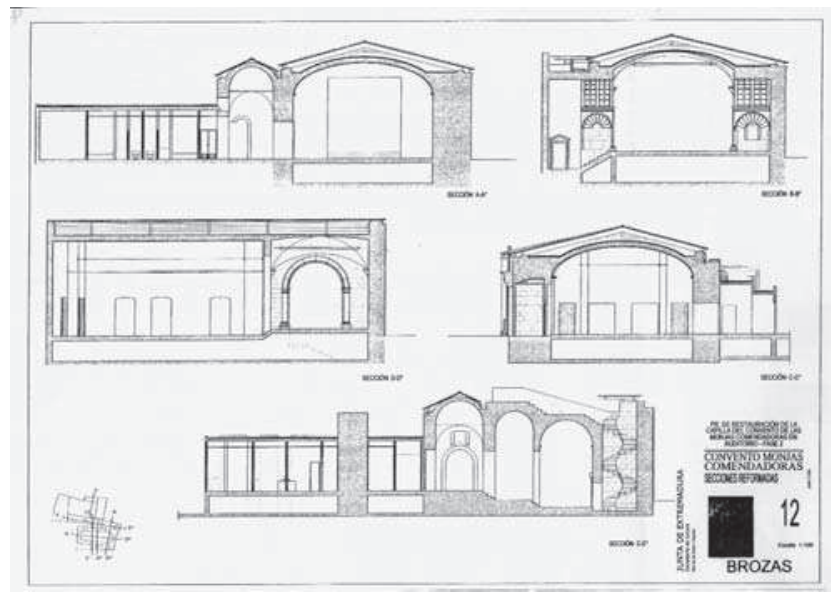

14. Convento de San Pedro de Brozas (Cáceres). Iglesia. Secciones. Estado reformado. $M^{a}$ VICTORIA DOMÍNGUEZ SERRANO.

aprovechan al máximo y potencian tanto el espacio existente como los de nueva construcción. La trepanación de los muros de la sacristía desvirtúa, sin embargo, la comprensión de este espacio ahora de tránsito y antes de recogimiento. Si bien hay que considerar que es un sacrificio menor, clave como nexo entre lo nuevo y lo antiguo.

Respetuoso es también el acoplamiento de pabellones de servicios en la zona del huerto. Su empleo plural no distorsiona la visión del monumento, maximiza el espacio escenográfico a cielo abierto, un uso y disposición que juzgamos singular, inteligente y atrevido.

Es respetuoso y coherente, así mismo, el acoplamiento de la cubierta de la capilla a los muros a través de un perfil metálico, como separación removible de lo nuevo frente a lo antiguo ${ }^{92}$, y muy loable la diferenciación del material repuesto, con un tono más claro que el de la piedra, sin estridencias.

Pero la actuación de la primera fase ha tratado a los paramentos y cubiertas de modo agresivo. Si bien es acertado partir de una excavación arqueológica, el hecho de efectuarla de modo total ha puesto en peligro la estabilidad del edificio ${ }^{93}$. Además la incorporación de hormigón armado en la cubierta del buque, vuelve la bóveda demasiado pesada y rígida, lo que provocará continuas fisuras en los puntos de intersección con las paredes como es visible en las humedades que presenta en la parte alta del muro de los pies. También provoca flectación en los tejados, ya ligeramente abarqui-

92 Art. 33, c), de la Ley de Patrimonio Histórico y Cultural de Extremadura 2/1999, de 29 de marzo de 1999. 93 Carta de Cracovia 2000, punto 10. 


\section{Q: artículos $\quad M^{a}$ del Carmen Diez González}

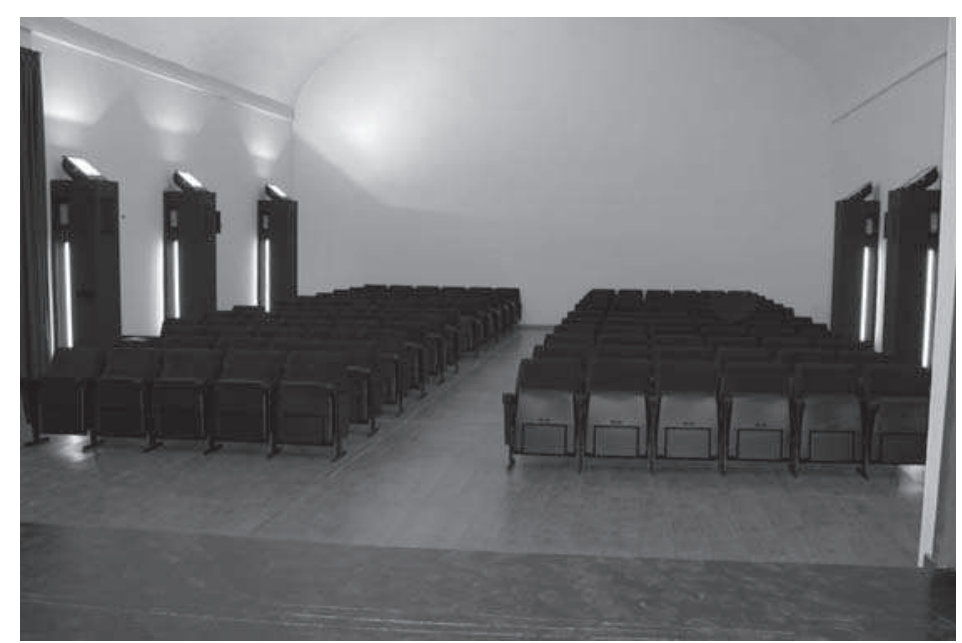

15. Convento de San Pedro de Brozas (Cáceres). Iglesia. Interior. Estado reformado. Vista desde la cabecera.

llados, que pueden dar lugar a encharcamientos y goteras. Por otra parte no es acertado el acabado con hormigón de las techumbres planas, debió hacerse con gravilla, como estaba previsto ${ }^{94}$, o lechadas de cal, material impermeable mucho más flexible y resistente a los fuertes desniveles de temperaturas que se sufren en la Alta Extremadura, donde se registran más de 30 grados de oscilación térmica.

En cuanto a la marquesina sobre la escalera de San Gil, resulta estética, atrevida y novedosa, pero no impide la estanqueidad del caracol, que de por sí ya es un monumento histórico-artístico, ni tampoco de los espacios a los que conduce. Al menos debería haberse realizado una puerta más hermética en la base. Quizás convenga revisar también el vuelo de esta marquesina para preservar el monumento frente al agua de lluvia y el viento. Tampoco se ha seguido el Art. 41. 5 de la Ley de Patrimonio Histórico y Cultural de Extremadura 2/1999, de 29 de marzo de 1999, referente a las instalaciones eléctricas y telefónicas, pues persisten los cables en la fachada.

Resulta criticable, así mismo, el tratamiento en profundidad de herbicidas y funguicidas, por poner en peligro la coexistencia de la piedra95.

La segunda fase mucho más respetuosa optó por el empleo de materiales tradi-

94 "Regularizar la cubierta de azotea... intentando homogeneizar todo el espacio con una terminación de gravilla aglomerada". $\mathrm{M}^{\mathrm{a}}$ del Carmen Sanz Gimeno. 'Memoria' del Proyecto "Auditorio del Convento de las Comendadoras", 1999, pág. 9.

95 Carta de Cracovia 2000, ibídem. 


\section{Q: artículos $\quad$ Proyecto de restauración del convento de las Monjas...}

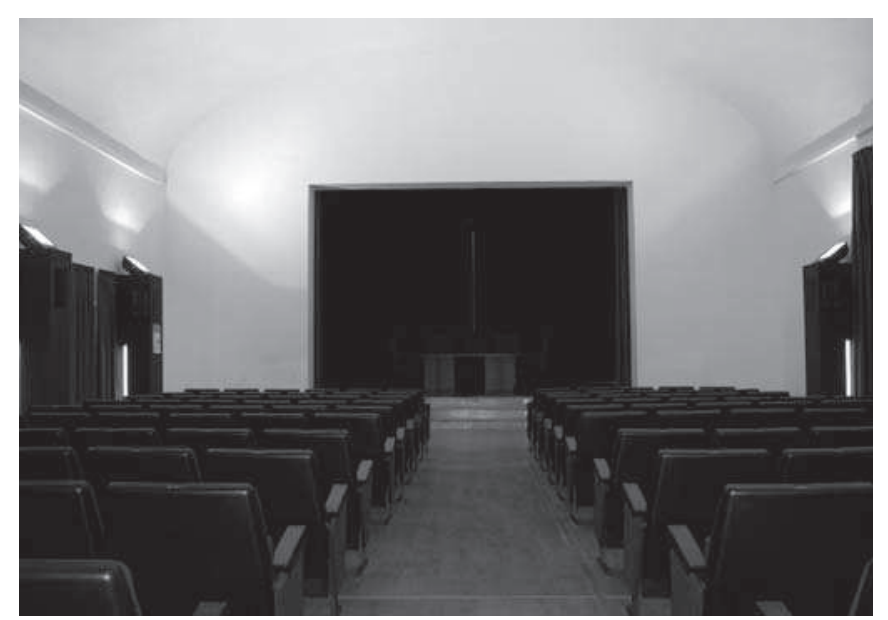

16. Convento de San Pedro de Brozas (Cáceres). Iglesia. Interior. Estado reformado. Vista desde el patio de butacas.

cionales removibles, aplicados a los morteros de los muros, a base de cal. Realizó un enzunchado interno de ladrillo y cal para estabilizar lo que el estudio arqueológico había dañado. Incluso la incorporación de elementos de elasticidad a los morteros de hormigón en las nuevas estructuras parecen augurar una mejor estabilidad de lo construido.

Sobre la tercera fase, actualmente en curso, creemos conveniente enjuiciarla una vez que se haya completado. Confiamos no obstante que el remate de la obra sea satisfactorio y respetuoso con el ambiente. 
